\title{
Enantioselective Palladium-Catalyzed Dearomative Heck Reaction
}

\section{Key words}

palladium catalysis

dearomatization

Heck reaction

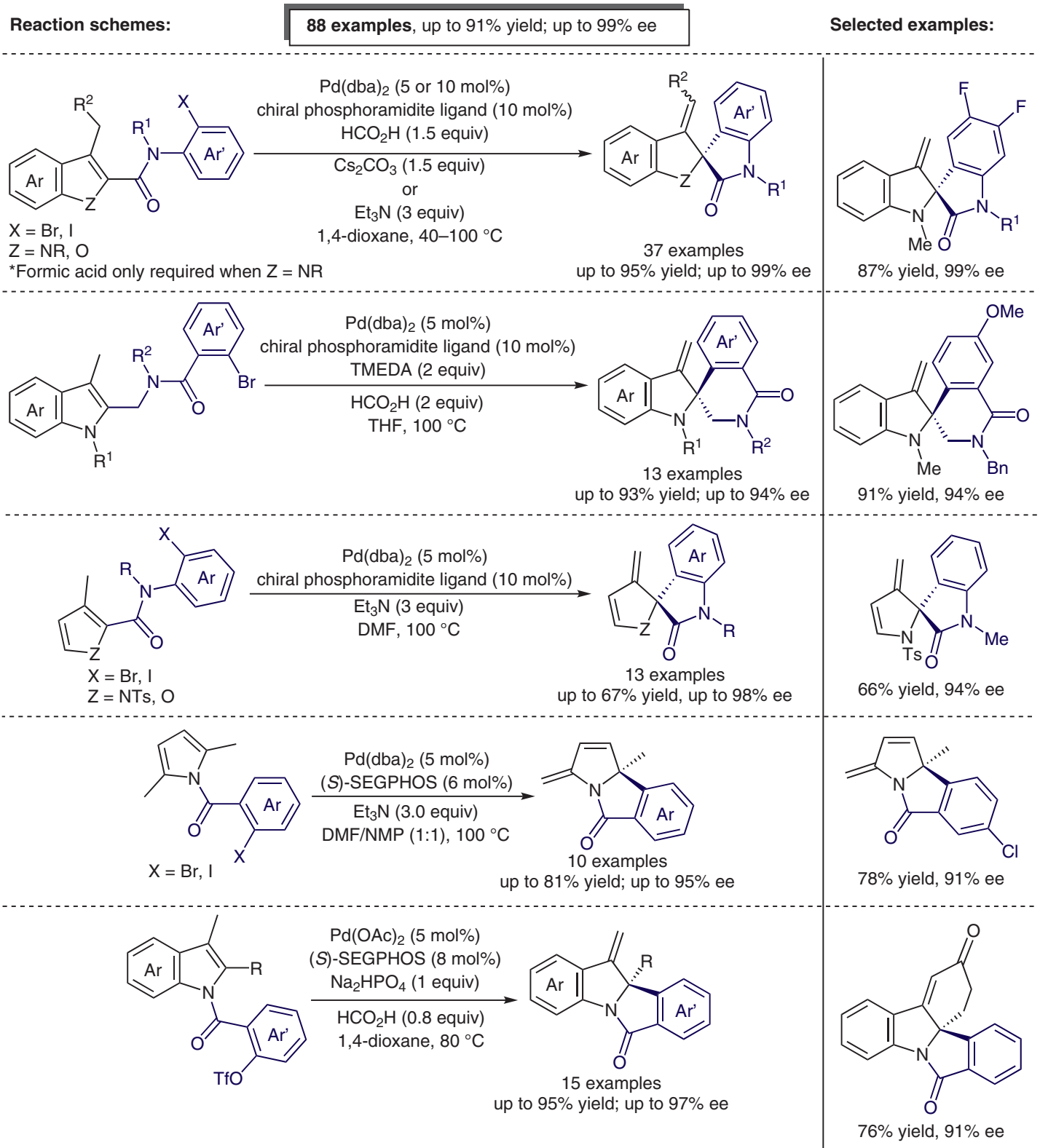

Significance: The authors report an enantioselective palladium-catalyzed dearomative Heck process, which affords a variety of spiroheterocycles and benzo-fused heterocycles in high yields and enantioselectivities.
Comment: Various sets of conditions were developed, depending on the heterocyclic scaffold employed. A remarkable number of examples (88) were demonstrated, and the synthetic utility of the products was displayed by a series of derivatizations. 